\title{
The "Bilio-Papillary Z Line": Proposal for a Novel Quality Indicator of Direct Cholangioscopy
}

\author{
Vincent Zimmer ${ }^{1,2}$ \\ ${ }^{1}$ Department of Medicine, Marienhausklinik St. Josef Kohlhof, Neunkirchen, ${ }^{2}$ Department of Medicine II, Saarland University Medical Center, \\ Saarland University, Homburg, Germany
}

Direct cholangioscopy (DC) provides high-quality endoscopic visualization of the biliary mucosa and has gained momentum in recent years, given the staggering technological and technical advancements. However, validated and/or conceptual quality indicators which are increasingly proposed for various endoscopic procedures remain poorly defined, focusing on pre-defined clinical targets (e.g., indeterminate strictures as per endoscopic retrograde cholangiography and/ or endoscopic ultrasound/other imaging findings) or on scope advancement up to the hilum. ${ }^{1}$ Thus, there is widespread consensus on presumed procedural completeness, i.e., advancement, up to a pre-defined target lesion and/or the liver hilum. By contrast, visualization of the most distal part of the common bile duct, i.e., the transitional zone from the biliary to the papillary mucosa, has been neglected in practice and research, mostly because of technical difficulties in stabilizing the endoscopic vision because of the sharp angulation of the duodenum-bile duct axis.

A novel quality indicator of DC, described in its freehand fashion without ancillary techniques, is being proposed and illustrated: ${ }^{2}$ the "bilio-papillary Z line" reminiscent of its more easily accessible esophago-gastro-duodenoscopy counterpart. A $360^{\circ}$ visualization of the bilio-papillary junction, in particular its medio-cranial aspects, remains difficult to achieve

Received: April 10, 2018 Revised: May 11, 2018

Accepted: May 11, 2018

Correspondence: Vincent Zimmer

Department of Medicine, Marienhausklinik St. Josef Kohlhof, Klinikweg 1-5, Neunkirchen 66539, Germany

Tel: +49-6821-3632070, Fax: +49-6821-3632624, E-mail: vincent.zimmer@gmx.de ORCID: https://orcid.org/0000-0002-6298-4717

(cc) This is an Open Access article distributed under the terms of the Creative Commons Attribution Non-Commercial License (http://creativecommons.org/ licenses/by-nc/3.0) which permits unrestricted non-commercial use, distribution, and reproduction in any medium, provided the original work is properly cited. with currently established techniques (Fig. 1A, B). Likewise, because of prolapsing papillary mucosa, adequate endoscopic vision of the bilio-papillary transitional zone may become blurred (Fig. 1C), highlighting the need for technical advancements to gently flatten abundant papillary mucosa comparable to, though less aggressive than, endoscopic papillary large balloon dilation (Fig. 1D). ${ }^{3}$ Further research on this topic and future technical/technological refinements, e.g., dedicated cap-assisted freehand-intubated cholangioscopy as is in clin-

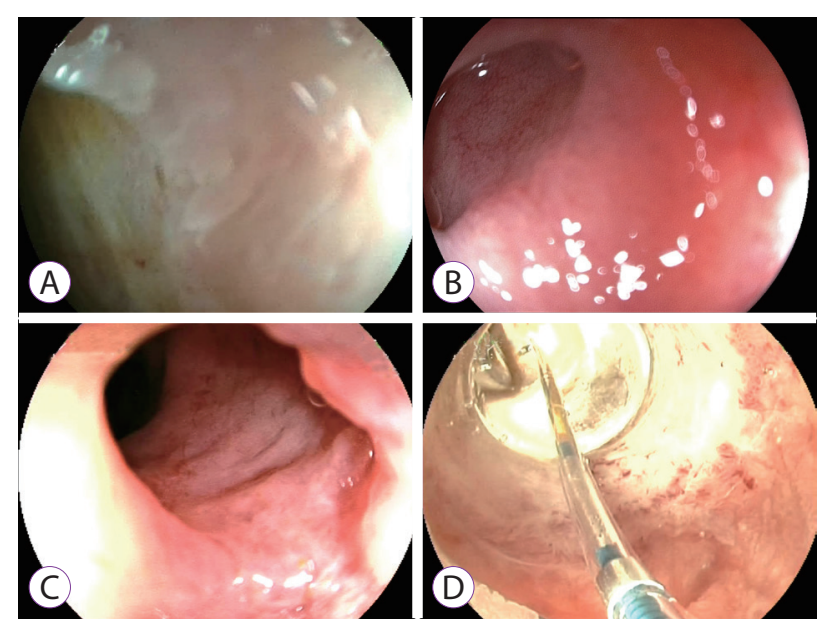

Fig. 1. The "bilio-papillary Z-line" during freehand-intubated direct cholangioscopy (DC) using an ultra-slim upper endoscope (Fujinon EG-530NW; Fujifilm, Düsseldorf, Germany) (A, B) or standard-size endoscope (Fujinon EG590WR; Fujifim) (C). Apart from adequate scope stabilization in the acute angulation of the duodenum-bile duct axis, comprehensive endoscopic visualization of the bilio-papillary transitional zone may be impeded by prolapsing papillary mucosa (C). Based on the current conceptual framework, technical refinements, such as dedicated cap-assisted DC may become instrumental in the future to flatten abundant papillary mucosa, comparable to, though less aggressive than, endoscopic large balloon dilation (CRE ${ }^{\mathrm{TM}}$ Balloon Dilatation Catheter; Boston Scientific, Ratingen, Germany), which is illustrated here in dilation-assisted freehand DC (D). 
ical evaluation, can warrant DC for truly complete visualization of the biliary mucosa.

\section{Conflicts of Interest}

The author has no financial conflicts of interest.

\section{REFERENCES}

1. Beyna T, Farnik H, Sarrazin C, Gerges C, Neuhaus H, Albert JG. Direct retrograde cholangioscopy with a new prototype double-bending cholangioscope. Endoscopy 2016;48:929-933.

2. Zimmer V. Novel biopsy forceps anchoring technique for completion of direct cholangioscopy after freehand intubation. Dig Endosc 2017;29:638-639.

3. Zimmer V. Knock-knock-knockin' on bile duct's door: the "tip-of-thebiopsy-forceps technique" - probing the route during freehand-intubated direct cholangioscopy. Endoscopy 2017;49:E153-E154. 